\title{
Modifikasi Persamaan Keausan Hip Prosthesis dengan Mempertimbangkan Koefisien Gesek
}

\author{
Eko Saputra ${ }^{1 *}$, Iwan Budiwan Anwar ${ }^{2}$, J Jamari $^{3}$ \\ ${ }^{1}$ Jurusan Teknik Mesin, Politeknik Negeri Semarang \\ Jl. Prof. H. Soedarto S.H., Tembalang, Semarang 50275, Telp. +62247473417 \\ ${ }^{2}$ Departemen Orthopedi dan Traumatologi, RS Ortopedi Prof. dr. R. Soeharso \\ Jl. A. Yani Pabelan, Surakarta 57162, Indonesia \\ ${ }^{3}$ Departemen Teknik Mesin, Universitas Diponegoro \\ J1. Prof. H. Soedarto, S.H., Tembalang, Semarang 50275, Telp. +62247460059 \\ *E-mail: eko.saputra@polines.ac.id
}

\begin{abstract}
Abstrak
Keausan pada tulang panggul buatan atau hip prosthesis merupakan fenomena yang tidak bisa dihindari. Informasi keausan pada hip prosthesis perlu diketahui dalam mempertimbangkan perancangan hip prosthesis. Pada tahun 2019 , penulis telah mengusulkan persamaan untuk menghitung keausan pada hip prosthesis. Hasil perhitungan persamaan keausan tersebut telah divalidasi dengan model keausan dimana hasilnya sangat sesuai. Akan tetapi, persamaan keausan tersebut belum melibatkan faktor koefisien gesek, karena diasumsikan bekerja pada daerah fully lubrication. Faktanya, interaksi kontak pada hip prosthesis dapat bekerja di daerah boundary lubrication dan mixed lubrication, sehingga penelitian ini sangat penting untuk dilakukan. Oleh karena itu, tujuan dari penelitian ini adalah memodifikasi persamaan keausan yang telah diajukan dengan mempertimbangkan koefisien gesek. Penelitian ini menggunakan metode observasi analitik. Persamaan keausan hip prosthesis secara analitik dikaji kemudian dikembangkan untuk memperoleh hasil yang sesuai yang diharapkan Hasil menunjukkan bahwa ada perbedaan nilai prediksi keausan hip prosthesis pada daerah boundary lubrication, mixed lubrication dan fully lubrication. Hasil keausan linier tertinggi terjadi pada jenis boundary lubrication, dibandingkan dengan hasil keausan dari persamaan sebelumnya memiliki deviasi sekitar $4.98 \%$. Keausan linier pada daerah mixed dan fully lubrication memiliki nilai yang hampir sama dengan deviasi sekitar $0.08 \%$, sedangkan jika dibandingkan dengan hasil keausan dari persamaan sebelumnya memiliki deviasi sekitar $0.97 \%$. Kesimpulan penelitian ini adalah persamaan keausan yang telah dimodifikasi mampu memprediksi keausan hip prosthesis dengan mempertimbangkan koefisien gesek.
\end{abstract}

Diterima: 02-08-2020; Direvisi: 22-08-2020; Dipublikasi: 01-09-2020

Kata kunci: pelumasan; persamaan keausan; tulang pinggul buatan

\begin{abstract}
Wear of hip prosthesis is a phenomenon that cannot be avoided. The wear information on hip prosthesis needs to be known in considering the design of hip prosthesis. In 2019, the authors have proposed an equation to calculate the wear on hip prosthesis. The results of the wear equation calculation have been validated with a wear model where the results are very suitable. However, the wear equation does not yet involve the coefficient of friction (COF), because it is assumed to work in the fully lubrication regime. In fact, contact interactions in hip prosthesis can work in boundary lubrication and mixed lubrication regimes, so this research is very important. Therefore, the purpose of this study is to modify the wear equation by considering the COF. This research uses analytical observation method. The hip prosthesis wear equation was analyzed analytically and then it was developed to obtain the desired results. The results show that there are differences in the predicted values for hip prosthesis wear in the boundary lubrication, mixed lubrication and fully lubrication regimes. The highest linear wear results occurred in the boundary lubrication, compared to the wear results from the previous equation which had a deviation of about $4.98 \%$. Linear wear on the mixed and fully lubrication regimes has a value that is almost the same with a deviation of about $0.08 \%$, whereas when compared with the wear results from the previous equation it has a deviation of about $0.97 \%$. The conclusion of this study is that the modified wear equation is able to predict the wear and tear of the hip prosthesis by considering the friction coefficient
\end{abstract}

Keywords: artificial hip joint; lubrication; wear equation

\section{Pendahuluan}

Ketika seseorang mengalami kecelakaan dan berakibat pada kerusakan tulang panggul, maka solusi yang bisa dilakukan adalah mengganti tulang panggul asli dengan tulang panggul buatan atau biasa disebut dengan hip prosthesis. 
Hip prosthesis juga bisa diterapkan bagi para pasien manula (manusia lanjut usia) yang mengalami keropos tulang panggul. Hip prosthesis tersusun dari beberapa komponen, diantaranya adalah femoral head, cup, liner dan stem seperti pada Gambar 1.

Solusi hip prosthesis sangat menguntungkan bagi pasien agar bisa melakukan kegiatan sehari-hari, akan tetapi hip prosthesis memiliki umur pakai. Umur pakai hip prosthesis dipengaruhi oleh dislokasi (lepasnya femoral head dari liner) dan keausan. Dislokasi bisa terjadi secara cepat bergantung dari perilaku pasien, sedangkan keausan dipengaruhi oleh waktu pemakaian dan material yang digunakan. Umumnya, umur hip prosthesis akibat keausan bisa diprediksi dengan menggunakan metode eksperimen, numerik dan analitik. Metode eksperimen, prediksi keausan bisa dilakukan dengan menggunakan bantuan hip simulator. Metode numerik, prediksi keausan bisa dilakukan dengan menggunakan bantuan software elemen hingga. Sedangkan, prediksi keausan secara analitik bisa dilakukan dengan persamaan keausan, dimana metode ini akan dibahas pada penelitian ini.
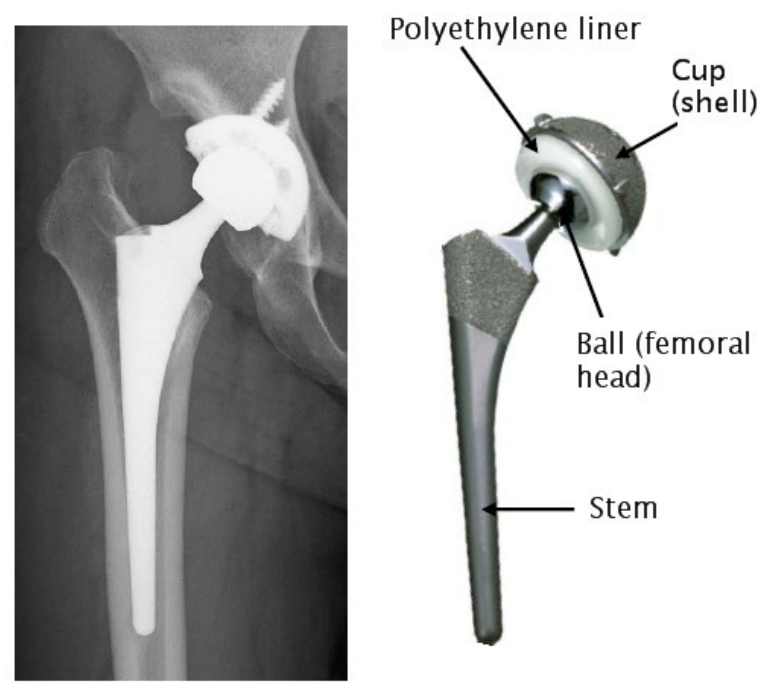

Gambar 1. Susunan tulang panggul buatan atau hip prosthesis [1]

Umumnya, prediksi keausan secara analitik dapat merujuk pada persamaan keausan Archard [2, 3], seperti pada Persamaan 1. Persamaan ini terdiri dari variabel volume keausan $V\left(\mathrm{~mm}^{3}\right)$, koefisien keausan tak berdimensi $k(-)$, gaya $F(\mathrm{~N})$, kekerasan $H$ dan jarak sliding $L(\mathrm{~mm})$.

$$
\frac{V}{L}=k \frac{F}{H}
$$

Persamaan ini telah digunakan dan dikembangkan oleh banyak peneliti untuk memprediksi keausan hip prosthesis. Pada tahun 1993, Dowson dkk. [4] telah mengembangkan persamaan Archard untuk memprediksi keausan pada pasangan head alumina dan liner UHMWPE. Selain itu, Dowson juga melakukan prediksi keausan secara eksperimen dan dibandingkan dengan hasil perhitungan analitik dalam bentuk grafik linear wear. Kauzlaric dkk. [5] pada tahun 2001 telah mengembangkan persamaan Archard dan membandingkan hasilnya dengan hasil eksperimen dowson, dimana hasilnya menunjukkan kecocokan dengan hasil eksperimen Dowson dalam bentuk linear wear. Liu dkk. [6] juga mengusulkan persamaan keausan yang berdasarkan hukum keausan Archard. Hasilnya ditunjukkan dalam bentuk grafik keausan liner dan volume wear. 
Baru-baru ini Saputra dkk. [7] juga telah mengusulkan persamaan keausan yang berdasarkan hukum Archard. Persamaan keausan ini telah dilakukan verifikasi dengan hasil eksperimen Dowson dan hasil perhitungan Kauzlaric. Kemudian persamaan ini digunakan untuk memprediksi keausan hip prosthesis akibat gerakan salat yang diwakilkan oleh sliding distance $L$ atau jarak sliding. Sliding distance akibat gerakan salat dapat dipengaruhi oleh range of motion yang telah dibahas pada penelitian sebelumnya [8]. Akan tetapi persamaan ini tidak mempertimbangkan faktor gesekan dalam perhitungan. Persamaan ini diasumsikan bekerja pada daerah fully lubrication. Padahal dalam kenyataan, pelumasan tidak selamanya dalam fully lubrication, bisa terjadi juga dalam kondisi boundary dan mixed lubrication, seperti Gambar 2 .

Jika melihat kurva stribek, pelumasan erat kaitannya dengan koefisien gesek. Setiap daerah pelumasan memiliki koefisien gesekan yang berbeda-beda. Melihat kondisi tersebut, maka koefisen gesekan perlu dilibatkan dalam persamaan keausan untuk mengetahui performa model hip prosthesis di ketiga daerah pelumasan tersebut. Berdasarkan penelusuran literatur, faktor gesekan dan pelumasan pada persamaan keausan untuk prediksi keausan hip prosthesis diwakilkan oleh nilai $K_{W}$ seperti Dowson dkk. [4], Kauzlaric dkk. [5] dan Liu dkk. [6]. Oleh karena itu, persamaan keausan yang mempertimbangkan faktor gesekan sangat diperlukan, dimana penelitian ini memiliki keterbaruan dari sisi penambahan faktor koefisien gesekan pada persamaan keausan hip prosthesis.

Tujuan dari penelitian ini adalah melakukan modifikasi persamaan keausan hip prosthesis dengan mempertimbangkan koefisien gesek. Hasil yang diperoleh dari penelitian ini adalah berupa persamaan keausan baru yang dapat digunakan untuk memprediksi keausan pada daerah boundary lubrication, mixed lubrication dan fully lubrication.

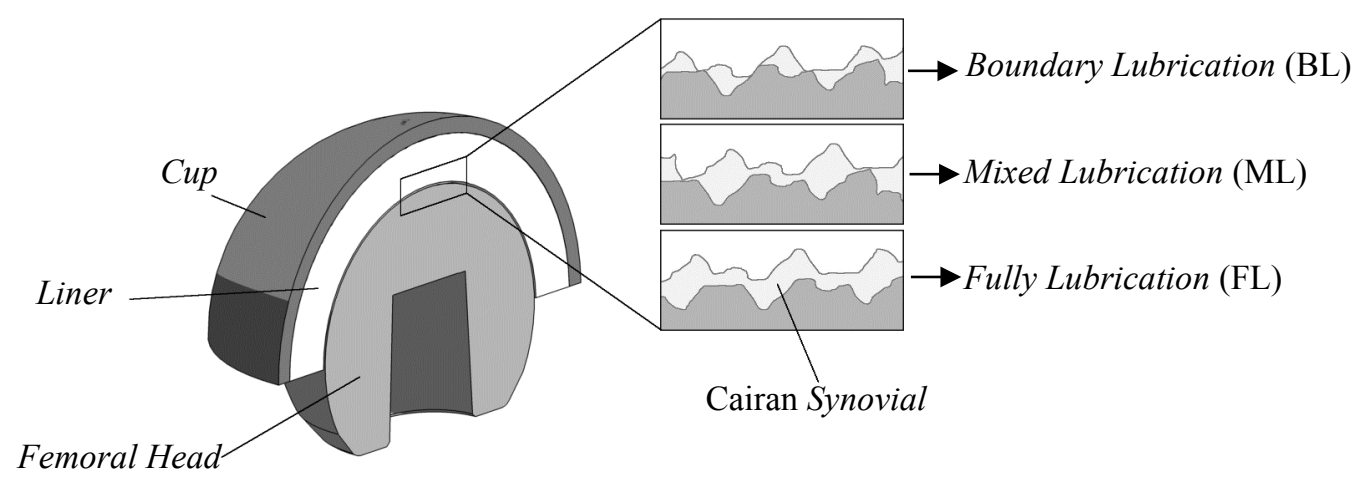

Gambar 2. Tiga daerah pelumasan pada hip prosthesis yang terdiri dari boundary lubrication, mixed lubrication dan fully lubrication, diadopsi dari [9]

\section{Material dan metodologi}

\subsection{Persamaan keausan (metode analitik)}

Penelitian ini menggunakan metode observasi analitik. Persamaan keausan hip prosthesis secara analitik dikaji kemudian dikembangkan untuk memperoleh hasil yang sesuai harapan. Pada tahun 2019, penulis telah mengusulkan persamaan keausan untuk memprediksi keausan pada hip prosthesis dengan mempertimbangkan gerakan salat, dapat dilihat pada Persamaan 2 [7]. Persamaan 2 tersusun dari keausan liner $h p$, koefisien keausan $K w$, gaya $F$, jari-jari Cup $R_{C}$, jari-jari $R_{H}$, jarak sliding $L$ dan jumlah siklus N. Persamaan 2 dibuat untuk menghitung keausan yang timbul akibat gesekan antara femoral head dan cup. Konsep keausan dengan mempertimbangkan susunan geometri head dan cup seperti Gambar 3. Penurunan persamaan hingga menjadi Persamaan 2, telah dijelaskan secara detail di artikel sebelumnya [7]. Dari Gambar 3, Persamaan 3 dan 4 ditunjukkan yang nantinya dapat digunakan pada penelitian ini, lebih detail bagaimana cara mendapatkan persamaan tersebut dapat dilihat pada penelitian Saputra dkk. [7]. 


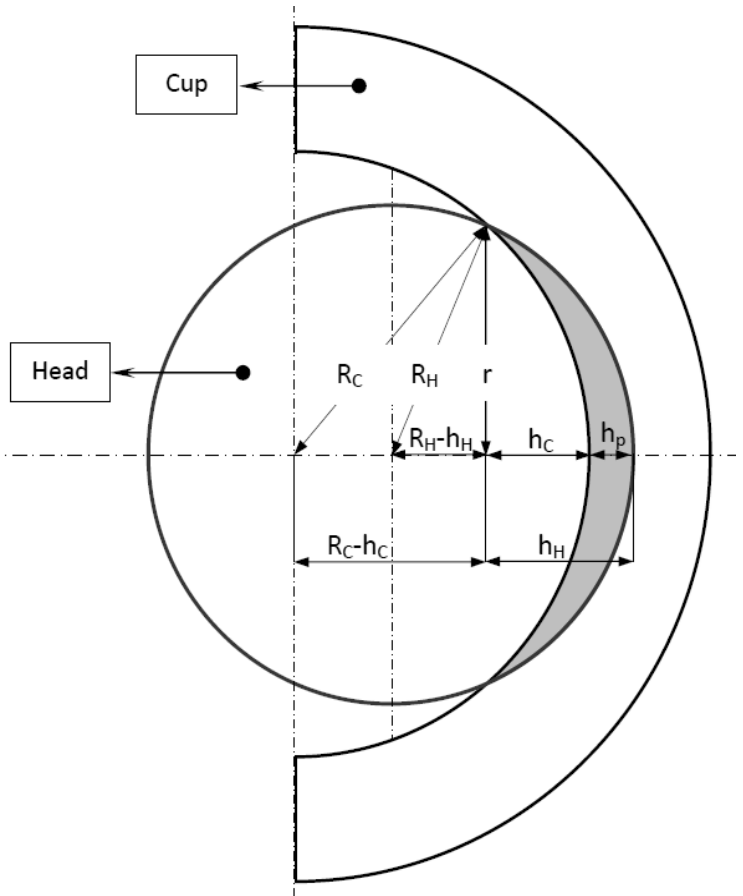

Gambar 3. Geometri keausan liner [7]

$$
\begin{aligned}
h_{P} & =\sqrt{\frac{K_{W} F\left(R_{C}-R_{H}\right)^{3} L R_{H} N}{\pi R_{C}^{3} R_{H}}} \\
h_{H} & =\frac{R_{C} h_{P}}{R_{C}-R_{H}} \\
r_{H}^{2} & =2 R_{H} h_{H}
\end{aligned}
$$

\subsection{Pelumasan dan koefisien gesek}

Persamaan 2 dibangun dengan asumsi hip prosthesis beroperasi pada daerah yang penuh dengan cairan synovial di dalam jaringan tubuh. Jika merujuk pada Gambar 4, Persamaan 2 tidak mempertimbangkan daerah pelumasan. Gambar 4 menunjukkan hubungan antara film thickness/roughness dan coefficient of friction [10]. Daerah pelumasan dibagi menjadi tiga daerah, yaitu boundary lubrication, mixed lubrication dan fully lubrication. Daerah pelumasan pada hip prosthesis dapat diketahui dengan melihat nilai film thickness/roughness, $\lambda$.

1) Boundary lubrication: $\lambda<1$

2) Mixed lubrication: $1<\lambda<3$

3) Fully lubrication: $\lambda>3$

Berdasarkan literatur, boundary lubrication memiliki nilai koefisien gesek $\mu$ dengan rentang 0,17-0,38. Mixed lubrication memiliki nilai koefisien gesek $\mu$ dengan rentang 0,05-0,17. Terakhir, fully lubrication memiliki nilai koefisien gesek $\mu$ dengan rentang 0,06-0,17. 


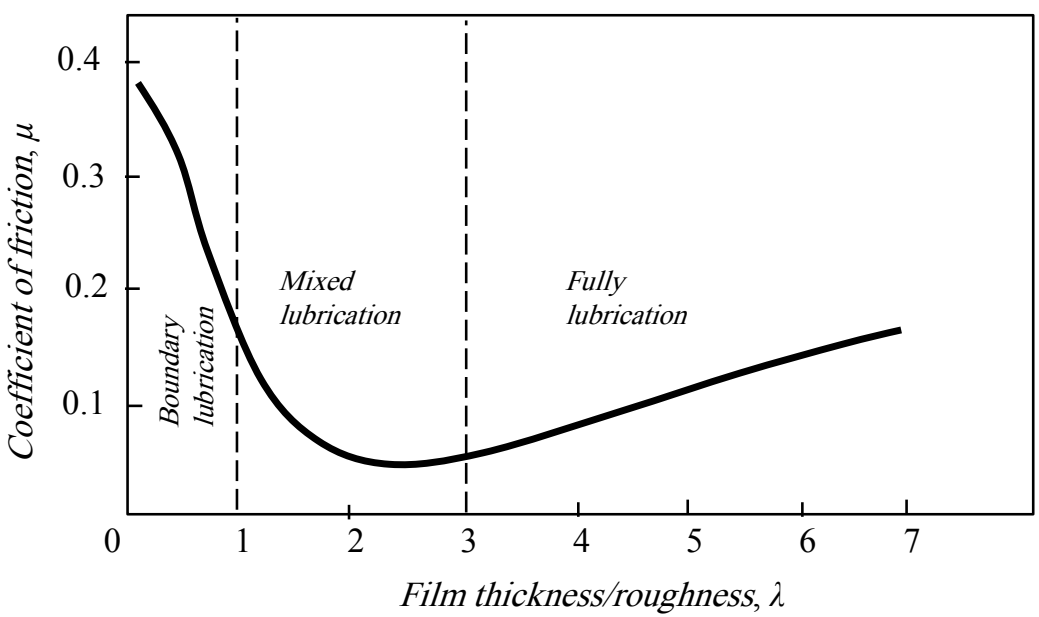

Gambar 4. Hubungan antara koefisien gesek dan nilai $\lambda$ untuk menentukan daerah pelumasan, diadopsi dari [10]

\subsection{Modifikasi persamaan}

Persamaan 2 dianggap bekerja pada daerah fully lubrication. Untuk bisa menghitung keausan dengan memperhitungkan daerah lubrikasi, maka Persamaan 2 perlu dimodifikasi. Pada modifikasi ini, model gesekan mengadopsi persamaan Sarkar yang telah digabung dengan persamaan Archard [2] sesuai dengan Persamaan 5.

$$
\frac{V}{L}=k \frac{F}{H} \sqrt{1+3 \mu^{2}}
$$

Jika $k_{w}=\frac{k}{H}$, dimana koefisien keausan berdimensi atau specific wear rate $k_{w}\left(\mathrm{~mm}^{3} / \mathrm{Nm}\right)$ maka diperoleh Persamaan 6 ,

$$
\frac{V}{L}=k_{w} F \sqrt{1+3 \mu^{2}}
$$

Jika $S_{e}=\sqrt{1+3 \mu^{2}}$, maka Persamaan 6 menjadi Persamaan 7

$$
\frac{V}{L}=K_{w} F S_{e}
$$

Dengan membagi kedua sisi dari Persamaan 7 dengan kontak area A maka diperoleh Persamaan 8, dimana keausan linier $h_{H}$ dan tekanan $P$.

$$
\frac{h_{H}}{L}=K_{w} P S_{e}
$$

Bentuk differensial dari Persamaan 8 ditunjukkan pada Persamaan 9,

$$
\frac{d h_{H}}{d L}=K_{w} P S_{e}
$$

Jika $P=\frac{F}{\mu r_{H}^{2}}$, maka Persamaan 9 menjadi Persamaan 10,

$$
\frac{d h_{H}}{d L}=K_{W} \frac{F}{\pi r_{H}^{2}} S_{e}
$$

Substitusikan Persamaan 4 ke Persamaan 10 sehingga diperoleh Persamaan 11, 


$$
\frac{d h_{H}}{d L}=K_{W} \frac{F}{2 \pi R_{H} h_{H}} S_{e}
$$

Mengintegrasikan $h_{H}$ sehubungan dengan $L$ sehingga diperoleh Persamaan 12-14,

$$
\begin{aligned}
& \int h_{H} d h_{H}=K_{W} \frac{F}{2 \pi R_{H}} S_{e} \int d L \\
& \frac{h_{H}^{2}}{2}=K_{W} \frac{F}{2 \pi R_{H}} S_{e} L \\
& h_{H}^{2}=K_{W} \frac{F}{\pi R_{H}} S_{e} L
\end{aligned}
$$

Substitusi Persamaan 3 ke Persamaan 14 sehingga diperoleh Persamaan 15-17,

$$
\begin{aligned}
& \left(\frac{R_{C} h_{P}}{R_{C}-R_{H}}\right)^{2}=K_{W} \frac{F}{\pi R_{H}} S_{e} L \\
& h_{P}^{2}=K_{W} \frac{F\left(R_{C}-R_{H}\right)^{2}}{\pi R_{C}^{2} R_{H}} S_{e} L \\
& h_{P}=\sqrt{\frac{K_{W} F\left(R_{C}-R_{H}\right)^{2} S_{e} L}{\pi R_{C}^{2} R_{H}}}
\end{aligned}
$$

Untuk jarak sliding pada kondisi berjalan gunakan $L=1.65 R_{H}[11,12]$ dan tambahkan variabel $N$ untuk mengetahui nilai keausan dalam sejumlah siklus, maka diperoleh Persamaan 18.

$$
h_{P}=\sqrt{\frac{K_{W} F\left(R_{C}-R_{H}\right)^{2} S_{e} 1.65 R_{H} N}{\pi R_{C}^{2} R_{H}}}
$$

Persamaan 18 inilah yang kemudian akan digunakan untuk memprediksi keausan dengan mempertimbangkan koefisien gesek pada daerah boundary lubrication, mixed lubrication dan fully lubrication.

\section{Hasil dan pembahasan}

\subsection{Validasi dan hasil modifikasi}

Berdasarkan Persamaan 18, diperlukan nilai variabel Sarkar dengan mengacu pada nilai koefisien gesek pada daerah boundary lubrication, mixed lubrication dan fully lubrication. Tabel 1 menunjukkan nilai data variabel Sarkar untuk keperluan dalam perhitungan dipenelitian ini. Selain itu, data lain yang diperlukan adalah specific wear rate dan gaya yang diterapkan masing masing $4.49 \times 10^{-7} \mathrm{~mm}^{3} / \mathrm{Nm}$ dan $3000 \mathrm{~N}$ yang diadopsi dari Dowson dkk. [3].

Tabel 1. Nilai variabel Sarkar dengan mengacu nilai COF

\begin{tabular}{lll}
\hline Daerah lubrikasi & $\mathrm{COF}, \mu[10]$ & Nilai rata-rata variabel Sarkar, $S_{e}$ \\
\hline Boundary lubrication & $0.17-0.38$ & 1.107 \\
Mixed lubrication & $0.05-0.17$ & 1.017 \\
Fully lubrication & $0.06-0.17$ & 1.019 \\
\hline
\end{tabular}

Gambar 5 menunjukkan hasil validasi Persamaan 2 dan 18 terhadap model keausan Dowson dan Kauzlaric. Berdasarkan Gambar 5, Persamaan 2 menunjukkan hasil yang baik dibanding dengan model keausan Dowson [3] dan Kauzlaric [5]. Untuk hasil Persamaan 18 dibanding dengan Persamaan 2 dan model keausan lain menunjukkan hasil yang 
berbeda, dimana nilai keausan hasil Persamaan 18 menunjukkan nilai yang lebih besar dibandingkan nilai Persamaan 2 dan model keausan kauzlaric. Hal ini menunjukkan bahwa koefisien gesek berpengaruh pada hasil perhitungan persamaan keausan.

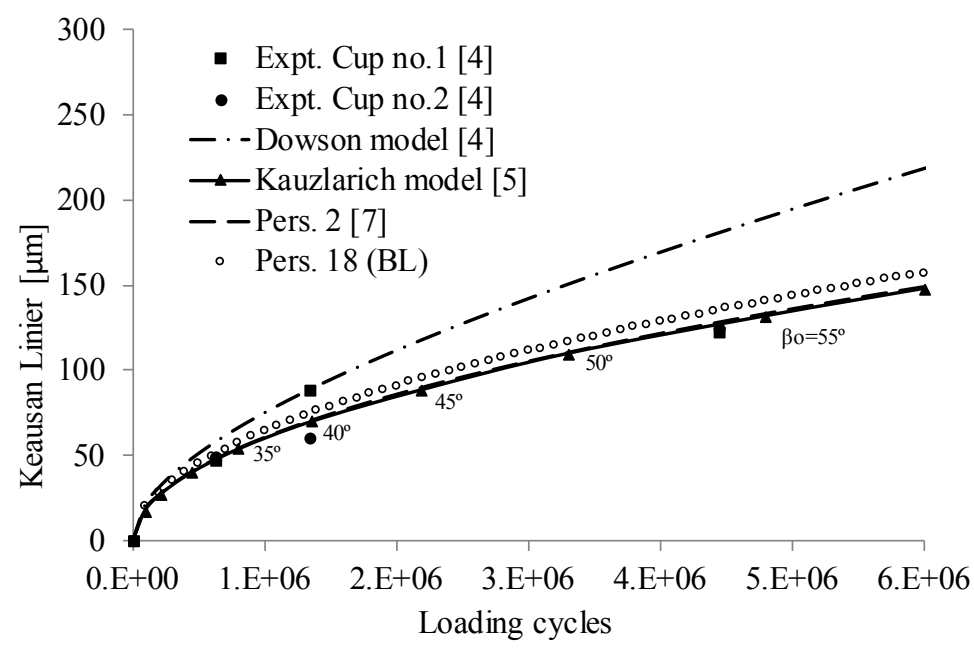

Gambar 5. Validasi Persamaan 2 dan 18 dengan model keausan Dowson [3] dan Kauzlaric [5]

\subsection{Prediksi keausan hip prosthesis pada tiga daerah pelumasan}

Gambar 6 menunjukkan perbandingan keausan linier berdasarkan Persamaan 18 dan nilai variabel Sarkar sesuai Tabel 1 untuk ketiga daerah pelumasan. Dengan menjadikan nilai keausan hasil dari Persamaan 2 sebagai acuan, maka dapat diketahui pengaruh dari daerah pelumasan. Prediksi keausan linier untuk daerah BL berada pada posisi paling tinggi dibanding keausan linier pada daerah lubrikasi yang lain. Jika dibandingkan dengan nilai keausan hasil Persamaan 2, diperoleh deviasi sekitar 4.98\%. Prediksi keausan linier untuk daerah ML dan FL menunjukkan hasil yang hampir sama dengan deviasi sekitar 0.08\%. Jika keausan linier BL dan ML dibandingkan dengan keausan linier Persamaan 2 diperoleh deviasi sekitar $0.97 \%$. Hasil penelitian ini menunjukkan bahwa, koefisien keausan dapat mempengaruhi hasil perhitungan keausan linier. Penelitian ini dapat digunakan untuk mendukung penelitian yang telah dilakukan sebelumnya yang berkaitan dengan interaksi kontak pada hip prosthesis $[13,14,15]$.

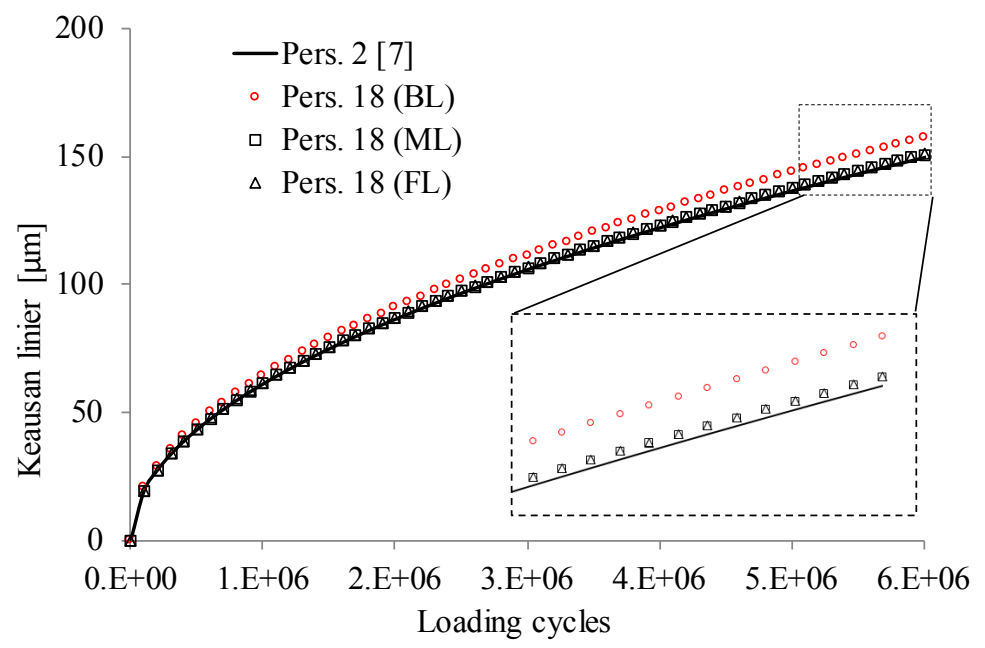

Gambar 6. Perbandingan keausan linier antara tiga daerah pelumasan dengan Persamaan 2 


\section{Kesimpulan}

Modifikasi persamaan keausan hip prosthesis dengan mempertimbangkan koefisien gesek telah dilakukan. Hasil persamaan hasil modifikasi menunjukkan perbedaan keausan di tiap jenis daerah pelumasan. Hasil keausan linier tertinggi terjadi pada jenis boundary lubrication, dibandingkan dengan hasil keausan dari persamaan sebelumnya memiliki deviasi sekitar 4.98\%. Keausan linier pada daerah mixed dan fully lubrication memiliki nilai yang hampir sama dengan deviasi sekitar $0.08 \%$, sedangkan jika dibandingkan dengan hasil keausan dari persamaan sebelumnya memiliki deviasi sekitar $0.97 \%$. Persamaan modifikasi yang mempertimbangkan koefisien gesek ini kemudian dapat digunakan untuk memprediksi untuk kasus-kasus lain serupa. Hasil prediksi keausan menggunakan persamaan ini dapat digunakan untuk pertimbangan dalam merancang hip prosthesis.

\section{Daftar Pustaka}

[1] https://www.u-tokyo.ac.jp/focus/en/features/f_00001.html (Diakses pada tanggal 1 Agustus 2020).

[2] Archard, J.F., Hirst, W. Wear of metals under unlubricated conditions. Proc. R. Soc. Lond. 1956; A, 236. p. 3-55.

[3] Archard, J.F. Contact and rubbing of flat surfaces. J. Appl. Physics. 1953; 24: p. 981-988.

[4] Dowson, D., Jobbins, B. and Seyed-Harraf, A. An evaluation of the penetration of ceramic femoral heads into polythene acetabular cups. Wear. 1993; 162-164: p. 880-889.

[5] Kauzlarich, J.J., Williams, J.A. Archard wear and component geometry. Proceedings of The Institution of Mechanical Engineers. 2001; 215: p. 387-403.

[6] Liu, F., Galvin, A., Jin, Z., dkk. A new formulation for the prediction of polyethylene wear in artificial hip joints. Proceedings of The Institution of Mechanical Engineers Part H; 2011.225 (1). p 16-24.

[7] Saputra, E., Anwar, I.B., Jamari, J.,, van der Heide, E. A Wear Formulation of Total Hip Prosthesis for Salat Activity. International Review of Mechanical Engineering (I.RE.M.E.). 2019; 13 (1): p. 29-37.

[8] Jamari, J., Anwar, I.B., Saputra, E., dkk. Range of motion simulation of hip joint movement during salat activity. The Journal of Arthroplasty. 2017; 32 (9): p. 2898-2904.

[9] Sonntag, R., Reinders, J., Rieger, J.S., dkk. Hard-on-Hard Lubrication in the Artificial Hip under Dynamic Loading Conditions. PLoS ONE. 2013; 8(8): e71622.

[10] Hutchings, I.M. Tribology: friction and wear of engineering materials. Edward Arnold, Great Britain. 2017; p. 141.

[11] Saikko, V. A three-axis hip joint simulator for wear and friction studies on total hip prosthesis, Proceedings of The Institution of Mechanical Engineers Part H; 1996. 210. p 175-185.

[12] Saikko, V., Ahlroos, T. Type of motion and lubricant in wear simulation of polyethylene acetabular cup. Proceedings of The Institution of Mechanical Engineers Part H; 1999. 213. p 301-310.

[13] Saputra, E., Anwar, I.B., Jamari, J., van der Heide, E. A bipolar artificial hip joint design for contact impingement reduction. Advanced materials research. 2015; 1123: p. 164-168.

[14] Saputra, E., Anwar, I.B., Ismail, R., Jamari, J., van der Heide, E. Study of unipolar and bipolar hip prosthesis using finite element simulation: contact stress analysis. Key Engineering Materials. 2017; 739: p. 96-102.

[15] Jamari, J., Ismail, R., Anwar, I.B., Saputra, E., Tauviqirrahman, M., van der Heide, E. Study the effect of surface texturing on the stress distribution of UHMWPE as a bearing material during rolling motion. AIP Conference Proceedings; 2016. 1725 (1). p 020030. 